\title{
Employee Productivity and Revenue-Based Model in Human Resource Accounting: An Empirical Study in Service Based Industries
}

\author{
Uma Hattikal ${ }^{1}$, Dr. Prakash $\mathbf{M}^{2}$ \\ ${ }^{1}$ PhD Research Scholar, Jain University, Bangalore, India \\ ${ }^{2}$ Director of Studies, Sheshadripuram Education Institutions
}

\begin{abstract}
Human resource accounting (HRA) is the process of recognizing and reporting the investments an organisation makes in its human resources (HR). Such a process is not mandated at least in the Indian organisational milieu as of now. Naturally, HRA views the organization's management and employees as human capital that generates benefits in the future. HRA attempts to value the organization's HR as an asset and not as an expense. Presently, HR is viewed as an expense item since it is expensed out by the organisation in its financials. In this paper it is elaborately discussed about the objectives and process of HRA in the Indian context in service industries. The basic objective of the paper is to study the Human Capital which is the most important intangible asset and how it affects an organisation's productivity, Human Resources Accounting practices, to identify the issues and challenges, to examine these issues and challenges and lastly, to give suggestions based on the findings of the study.
\end{abstract}

Keywords: Human resource accounting, Human Capital, Physical Assets, Human Resource Accounting (HRA)

\section{Introduction}

Human resource accounting is the procedure to recognize and report the investments made in the Human Resources of an Organization that are currently not accounted for in the conventional accounting practices. Human Resource Accounting is a Process of Identifying and Measuring data of Human Resources and Communicating this Information to ten interested parties. It is an attempt to identify and report the Investments made in Human Resources of an Organisation that are currently not accounted for in the Conventional Accounting practices. Normally, human resource Accounting (HRA) engages accounting for the organization's management and employees as human capital that provides future benefits. Human Resource Accounting believes accounting for people is effectively accounting for organizational resources. HRA is the measurement of the cost and value of people to organization.

HRA involves assessing costs incurred by private firms and public sectors to recruit, select, employ, train and develop employees and assessing their economic value to the organization.

Human resource accounting is a complicated way to determine in financial terms the effectiveness of the personnel manager"s activities and the use of people in an organization.

HRA is process of accounting people as an organizational resource.

HRA attempts to place a value on the organization,s human resources as assets and not as expenses.

Thus, Human Resource Accounting is a term applied by Accountancy Professional to quantify the cost and Value of Employees of their employing Organisation.

\section{Motivation and Problem Statement}

The logic behind viewing $\mathrm{HR}$ as an asset too is understandable. After all, accounting for the HR of an organisation virtually amounts to accounting for the people that make the organisation. HRA is the measurement of the cost inflicted by the HR on the organisation and the value the HR / people bring to the organization. The American Accounting Association Committee defines it comprehensively when it says, "Human Resource Accounting is the process of identifying and measuring data about human resource and identifying and measuring data about human resource and communicating this information to interested parties." In simpler terms, HRA involves assessing the cost incurred by private firms and public sectors to recruit, select, employ, train and develop employees; and assessing their economic value to the organization. HRA is a complicated way of determining in monetary terms, the fruits of the personnel manager"s labours and the use of people in an organization. Thus it can be deduced that HRA should help in evolving effective management practices, in motivating the people behind the organization, in adding value to the said people through training and in planning physical resource. The long and short of it is that HRA considers HR as equivalent to other assets in the organization. In the circumstances, it is necessary to ascertain if the people that matter in the HRA space of the organisation, namely the C-suite executives from the finance and HR functions and the officers that report to them, amongst others, perceive HRA the way it should be perceived. And if they do, it is also necessary to ascertain from them the benefits that accrue to the organisation from HRA. Along the way, a few hiccups could arise too. If so, it is necessary to isolate the limitations that gave rise to the hiccups in the first place. The need to tackle these HRA-related problems motivated the researcher to take up this study.

\section{Definitions}




\section{International Journal of Science and Research (IJSR) \\ ISSN (Online): 2319-7064}

Index Copernicus Value (2013): 6.14 | Impact Factor (2014): 5.611

1) According to Dutta, the standard method of estimation of HRA is still in an evolving stage (Dutta, 2008). Accounting bodies across the world have not accepted any model of HRA as the benchmark for HRA. In India's knowledge-based IT sector, the Lev and Schwartz model with some customizations are considered for HRA.

2) Even though the accounting systems reckon human asset as expenses, in future the human asset will generate benefits (Sonbhadra, 2013). Managers can use human capital as a tool to achieve optimisation in the organisation "s expenditure on human capital.

3) Gupta remarks that the present accounting system does not assign a specific value to the knowledge of the employees (Sonbhadra, 2013). This in the long run affects the cost incurred to train and recruit manpower.

\section{Objectives of the Study}

1) Ascertain how the respondents perceive human resource accounting (HRA)

2) Study the modus operandi of HRA in the respondent organisations

3) Identify the benefits accruing from HRA, from the perspective of the respondents

4) Isolate the limitations of HRA, from the perspective of the respondents.

5) Design a HRA model that suits the service industries in the Indian milieu

5. Hypothesis to be tested

1) HRA is "accounting for people as an organizational resource

2) HRA represents the investment made by an organization in its people and reveals how the value of these people changes over time.

3) Investment in intellectual assets is a prerequisite for the service industry

4) Human resources should be capitalized as it yields benefits quantifiable in financial terms

5) HRA attempts to capitalize an organization,s human resources without viewing them as expenses

6) HRA is right in rejecting the established notion that all expenditure on human capital formation is a charge against the revenue of the period since the expenditure does not create any physical asset.

The difficulty in evaluating intellectual capital to the satisfaction of all stake-holders is a major limitation of HRA.

\section{Major Issues of Human Resource Accounting}

In the recent past, it has been observed that the value based measures of HRA are finding more acceptances with Flamholtz approach being progressively used. However, this approach depends heavily on the measurement of an individual's or a group $\mathrm{s} s$ contribution of valuation. But, measurement of contribution, especially at the managerial levels, is quite a difficult task. As a result, this factor proves to be a hindrance in the development of the concept of HRA.
The physical assets can be owned and traded by an organization but the human assets cannot and can be only utilized in this regard. The physical assets have some realizable value of retirement but the human resources do not have any such value. They may involve payments of retrenchment, compensation, gratuity and other benefits. Human resources is an appreciating asset since manpower improves with time, with due regard to their ageing constraint, but for physical asset its increasing value at the time of its installation, starts immediately depreciating.

If an individual is to be valued normatively, the model given by Flamholtz expects that the career path of individuals should be plotted over the span of his probable stay with the organization in the light of the current promotion, and retirement policies of the organization. But such exercise is tedious.

\section{Benefits of Implementing Human Resource Accounting in the Organisation}

1) Human Resource Accounting helps the company ascertain how much investment it has made on its employees and how much return it can expected from its investment.

2) The ratio of human Capital to Non human capital computed as per the Human Resource Accounting concept indicates the degree of labour Intensity of an Organisation.

3) Human Resource Accounting provides valuable information to Investors interested in making long term Investments in companies.

4) Human Resource Accounting provides a basis for planning of physical assets Vis- a Vis Human Resource.

By adopting and implementing HRA in an organization, the following important information could be obtained:

- Cost per employee

- Human Capital Investment Ratio

- The amount of wealth created by each employee

- The profit created by each employee

- The ratio of salary paid to the total revenue generated

- Average salary of each employee

- Employee absenteeism rates

- Employee turnover rate and retention rate

\section{Methodology of the Study}

The study is descriptive in nature and has used the ,factfindingee survey method.

\section{Methods of data collection}

Interview schedules specially designed for the purpose were administered to the respondents to collect primary data. The study involves collection of opinions / preferences from respondents; hence, interviewing was deemed appropriate. The interview was a structured / directive interview. Hence the interview was conducted with a detailed standardised schedule.

In addition, the Researcher interacted extensively with other stakeholders associated with the HRA space like trade and 


\section{International Journal of Science and Research (IJSR) \\ ISSN (Online): 2319-7064}

Index Copernicus Value (2013): 6.14 | Impact Factor (2014): 5.611

industry bodies consultants professional bodies to elicit their views and comments.

\section{Sources of Data}

Primary data has been collected from the respondents, viz, Chief Executives-HR, Chief Executives-Finance, Financial Consultants and HR Consultants.

Secondary data has been collected / downloaded in hard version / digital form, from the websites of CII, FICCI, ASSOCHAM, E\&Y, PwC, Deloitte, KPMG, ICAI, ICWAI, ICSI and the financial press.

\section{Sampling Plan}

Chief Executives-HR: Given the rather limited number of respondents representing the companies that operate in the area covered by the study, purposive or judgement sampling under the non-probability method was deployed. Applying the number of years of exposure to HR accounting as the criterion, the researcher selected 30 respondents, each with an exposure of at least three years to the HRA space. This criterion, according to the researcher, is the most appropriate one for the present study. What is important is the typicality and the relevance of the sampling units to the study and not the overall representativeness to the population. Thus it guarantees inclusion of the relevant elements in the sample. Probability sampling plans cannot give such a guarantee.

HR Consultants: Given the rather limited number of respondents into HR consulting in the area covered by the study, purposive or judgement sampling under the nonprobability method was deployed. Applying the number of years of exposure to HR accounting as the criterion, the researcher selected 60 respondents, each with an exposure of at least five years to the HRA space. This criterion, according to the researcher, is the most appropriate one for the present study. What is important is the typicality and the relevance of the sampling units to the study and not the overall representativeness to the population. Thus it guarantees inclusion of the relevant elements in the sample. Probability sampling plans cannot give such a guarantee.

Chief Executives-Finance: Given the rather limited number of respondents representing the companies that operate in the area covered by the study, purposive or judgement sampling under the non-probability method was deployed. Applying the number of years of exposure to HR accounting as the criterion, the researcher selected 30 respondents, each with an exposure of at least three years to the HRA space. This criterion, according to the researcher, is the most appropriate one for the present study. What is important is the typicality and the relevance of the sampling units to the study and not the overall representativeness to the population. Thus it guarantees inclusion of the relevant elements in the sample. Probability sampling plans cannot give such a guarantee.

Financial Consultants: Given the rather limited number of respondents into financial consulting in the area covered by the study, purposive or judgement sampling under the nonprobability method was deployed. Applying the number of years of exposure to HR accounting as the criterion, the researcher selected 60 respondents, each with an exposure of at least five years to the HRA space. This criterion, according to the researcher, is the most appropriate one for the present study. What is important is the typicality and the relevance of the sampling units to the study and not the overall representativeness to the population. Thus it guarantees inclusion of the relevant elements in the sample. Probability sampling plans cannot give such a guarantee.

\section{Data Collection Instruments}

Interview schedules, specially designed for the purpose, were drafted and pre-tested in order to identify the possible weaknesses in the instrument. Upon receipt of feedback, they were appropriately revised and finalised for administration to the respondents for collection of primary data.

The Interview Schedules featured open questions and closed questions. Open questions were included since the objective was to identify opinions, ascertain degrees of knowledge and seek suggestions and more information. In some cases, the subject matter of the question was outside the range of the respondent's experience and hence open questions were a better alternative. Further, open questions were of help in determining the depth of the feelings and expressions of intensity of the respondent. Open questions may give the respondent a chance to think through the topic. Since it was practically impossible for the Researcher to assess the level of information possessed by the respondent, open questions came in handy. The response freedom inherent in open questions elicited a variety of frames of references from the respondent, which may provide unanticipated insights. Given the qualitative nature of the values the variables elicit from the respondents, they lend themselves ideally to statistical tools like Likert scale and chi-squared test.

\section{Field Work}

Field work was undertaken by utilising the services of manpower suitably briefed for the purpose. The respondents were contacted individually and personally and their responses were recorded.

\section{Data Processing and Analysis Plan}

Non-parametric statistical units were used to test the association between some qualitative characters and conclusions were drawn on the basis of formation of $\mathrm{H}_{\mathrm{o}}$ and $\mathrm{H}_{1}$. To be specific, Likert scale and chi-square test were applied to test the hypotheses.

\section{Conclusion}

HRA views (and rightly so) human resources as an asset that is on a par with any other asset of an organisation, intangible though it is. Like any other asset, it is a resource that boasts of an economic value. The organisation owns and controls HR (as it does any other asset), hoping to generate income from it, in future too. An asset is supposed to enhance the value of the organisation. An asset is supposed to generate 


\section{International Journal of Science and Research (IJSR) \\ ISSN (Online): 2319-7064}

Index Copernicus Value (2013): 6.14 | Impact Factor (2014): 5.611

cash flows too, for the organisation. HRA fulfils these criteria too.
Education Institutions. He has been a author of many articles and books.

HR qualifies as capital too but of the intellectual kind. This is because intellectual capital is more durable than money. Intellectual capital is used to generate wealth through investment. HR generates wealth for the organisation thanks to the intellectual capital it brings in. Like traditional capital, HR can be rented by the organisation to create wealth.

Since HR qualifies as capital of the intellectual kind, HRA should be identified as a capital item. This renders it possible to quantify intellectual capital. Since HR qualifies as a capital asset, it represents the investment made by the organisation in its people.

\section{References}

[1] Dutta, S. (2008, March). HR-accounting - A Stratigic Use of Lev \& Schwartz Model.

[2] Lal, M. C. (2008). Human Resource Accounting: an Implication for Managerial Decisions in Indian Hotel Industry. Kurukshetra: International Journal of Hospitality \& Tourism Systems .

[3] Sonbhadra, S. B. (2013, December). A STUDY ON ACCOUNTING OF HUMAN RESOURCE VERSES PHYSICAL ASSETS. Retrieved october onday, 2015, from

http://www.internationalseminar.org/XV_AIS/TS\%205A 17.\%20Mr.\%20Shashi\%20Bhushan\%20Sonbhadra.pdf

[4] Lal, M. C. (2008). Human Resource Accounting: an Implication forManagerial Decisions in Indian Hotel Industry. Kurukshetra: International Journal of Hospitality \& Tourism Systems.

[5] Reeta, Z. H. (2012). Managerial uses of Human Resource accounting: A Survey. International Journal of Research in commerce and Management, 3 (9).

[6] Sackmann, S. F. (1989). Human Resources Accounting a state-of-art Review. Journal of Accounting Literature, 8, 235-264.

[7] Bullen, And Eyler, "Human Resource Accounting And International Developments: Implications For Measurement Of Human Capital", Journal of International Business And Cultural Studies, V, 2010, ISSN 1941-5087.

[8] CK Sonara, "valuation and Reporting Practices Of Human Resource Accounting In India”, The Accounting World, X (3), 2010, 50-55.

\section{Author Profile}

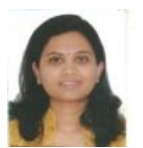

Uma Hattikal holds a Master of Business Administration from Visveswariah Technological University Belguam, a Bachelor Degree in Business Administration from Karnataka University, Dharwad and is Currently a Doctoral Student at Jain University, Bangalore India. She is working as a faculty in a Management College, Bangalore.

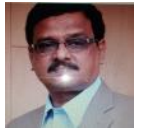

Dr Prakash $\mathbf{M}$ a $\mathrm{PhD}$ in Social Marketing, M Phil,M.Com from Bangalore University, has been full time academics for the past 3 decades. Presently working as Director of Studies in Sheshadripuram 